\title{
Myelodysplasia Associated with Acquired Immunodeficiency Syndrome
}

\author{
Tomiko Ryu, Masaki Ikeda, Yuko Okazaki, Hitoshi Tokuda, Naoto Yoshino*, \\ Mitsuo HondA*, Satoshi KIMURA** and Yasusada MiURA
}

\begin{abstract}
Two cases of acquired immunodeficiency syndrome with myelodysplasia are presented. Case 1 was admitted because of Pneumocystis carinii pneumonia. Mild anemia, thrombocytopenia and hypersegmented neutrophils were observed. After the administration of trimethoprim-sulfamethoxazole and antiretroviral therapy, pancytopenia progressed. Bone marrow (BM) showed dysplastic hematopoiesis, suggesting human immunodeficiency virus-myelopathy. Case 2 was hospitalized due to progressive multifocal leukoencephalopathy. BM specimen obtained for thrombocytopenia showed myelodysplasia similar to myelodysplastic syndrome, suggesting that HIV may have an influence on hematopoietic progenitor cells.

(Internal Medicine 40: 795-801, 2001)
\end{abstract}

Key words: human immunodeficiency virus (HIV) infection, pancytopenia, myelodysplastic syndrome, HIVmyelopathy, hematopoietic progenitor cells

\section{Introduction}

Hematologic abnormalities are found in most patients with human immunodeficiency virus (HIV) infection $(1,2)$, particularly in later phases of the disease. Anemia, leukopenia, thrombocytopenia or pancytopenia are often observed. However, the causes of these abnormalities are usually multifactorial, and commonly can be attributed to hematopoietic suppression of bone marrow due to infection or drugs. Dysplastic hematopoiesis is also a common finding accompanying HIV infection $(3,4)$. If the well-defined criteria for the diagnosis of myelodysplastic syndrome (MDS) are applied, most hemopoietic findings in acquired immunodeficiency syndrome (AIDS) do not correspond to the significant maturation defects comparable with MDS. In a large number of cases, bone marrow (BM) findings seem to be nonspecifically abnormal. Therefore, bone marrow lesions accompanying AIDS may be separated from MDS and diagnosed as HIV-myelopathy.

In this article we report two cases of AIDS with dysplastic hematopoiesis. HIV infection may induce HIV-myelopathy, or MDS results from the influence on hematopoietic progenitor cells (HPC), and MDS contributes to peripheral pancytopenia through ineffective hematopoiesis.

\section{Case Report}

\section{Case 1}

A 66-year-old man was admitted to our hospital on October 8,1998 , because of severe pneumonia. He had no past history except for hepatitis B.

On admission, laboratory data showed mild normochromic anemia (hemoglobin $12.0 \mathrm{~g} / \mathrm{dl}$ ) and thrombocytopenia (platelet count $9.6 \times 10^{4} / \mu \mathrm{l}$ ). The white blood cell (WBC) count was $6,000 / \mu 1$, and the differential revealed $73 \%$ neutrophils and $16 \%$ lymphocytes. Hypersegmentation of the neutrophils was observed. The levels of lactic acid dehydrogenase $(\mathrm{LDH})(1,249$ IU), C-reactive protein (CRP) $(18.2 \mathrm{mg} / \mathrm{dl})$ and $(1 \rightarrow 3)-\beta$-Dglucan $(>300 \mathrm{pg} / \mathrm{ml})$ were elevated. Analysis of arterial blood gas showed that the partial pressure of oxygen was $49.8 \mathrm{Torr}$, the partial pressure of carbon dioxide was 27.7 Torr, and $\mathrm{pH}$ was 7.465. Chest radiograph and chest computed tomography (CT) showed diffuse interstitial infiltrations. Pneumocystis carinii was detected from the bronchoalveolar lavage (BAL) fluid by Grocott staining and polymerase chain reaction (PCR). As HIV-1, 2 antibodies and Western blotting for HIV-1 antibody were both positive, he was diagnosed as having acquired immunodeficiency syndrome (AIDS) complicated with Pneumocystis carinii pneumonia (PCP). The CD4+ cell count was $37 / \mu l$ and HIV-1-RNA viral load was $8.6 \times 10^{4}$ copies $/ \mathrm{ml}$. Trimethoprim and sulfamethoxazole (TMP-SMX) with glucocorticoid therapy was effective, and PCP was improved. After about 1 month, highly active antiretroviral therapy (HAART), that is, zidovudine, lamivudine and nelfinavir was started. As

From the Department of Internal Medicine, Social Insurance Chuo General Hospital, Tokyo, *AIDS Research Center, National Institute of Infectious Diseases, Tokyo and **the Department of Infectious Diseases, Graduate School of Medicine, University of Tokyo, Tokyo

Received for publication July 24, 2000; Accepted for publication January 16, 2001

Reprint requests should be addressed to Dr. Tomiko Ryu, the Department of Internal Medicine, Social Insurance Chuo General Hospital, 3-22-1 Hyakunincho, Shinjuku-ku, Tokyo 169-0073 
WBC count was decreased to $1,300 / \mu 1$ (neutrophils $9 \%$ ) on November 9, granulocyte colony-stimulating factor (G-CSF) was administered. On November 12, he suffered from pneumonia again. Culture of BAL fluid yielded Aspergillus flavus. As the pneumonia was improved by the administration of amphotericin B, he was discharged on February 2, 1999 (Fig. 1).

As pancytopenia (WBC 2,700/ $\mu 1$, neutrophils 9\%, hemoglobin $10.4 \mathrm{~g} / \mathrm{dl}$, MCV $114.2 \mathrm{fl}$, platelet $7.3 \times 10^{4} / \mu \mathrm{l}$ ) developed, bone marrow (BM) was examined on February 22, 1999. Although BM cellularity was normal, morphologic abnormalities of giant stab, hypersegmentation and defective granulation of neutrophils, distorted nuclear and cytoplasmic maturation, multinucleation of erythroblasts were observed (Fig. 2). Chromosome analysis was $46, \mathrm{XY}$. The serum levels of vita$\min \mathrm{B} 12$ and folic acid were in the normal range.

\section{Case 2}

A 25-year-old man complained of fever on October 13, 1997 and one week later, language disturbance and difficulty with handwriting appeared. He was admitted to our hospital on November 5. He had been diagnosed as having HIV infection, and zidovudine had been administered in another hospital in December 1994. When he came to our out-patient clinic in November 1996, CD4+ cell count was $39 / \mu 1$ and platelet count, $7.5 \times 10^{4} / \mu 1$.

On admission, he did not show abnormal neurologic findings except for slight ataxia on the right upper extremities. His WBC count was $3,400 / \mu 1$ and the differential revealed $38 \%$ neutrophils and $44 \%$ lymphocytes. He showed thrombocytopenia (platelet count $6.1 \times 10^{4} / \mu 1$ ) without anemia. $C D 4+$ cell count was $91 / \mu 1$, and HIV-1-RNA viral load was $5.5 \times 10^{4}$ copies $/ \mathrm{ml}$. The culture of cerebrospinal fluid (CSF) was negative. A T2weighted magnetic resonance imaging (MRI) showed an increased high intensity signal in the white matter of bilateral frontal lobe. Didanosine and indinavir were started. At the end of November 1997, he showed hemiparesis on the right side. Platelet count was decreased to $4.5 \times 10^{4} / \mu \mathrm{l}$. The level of platelet associated IgG (PAIgG) was $73.5 \mathrm{ng} / 10^{7}$ cells (normal range

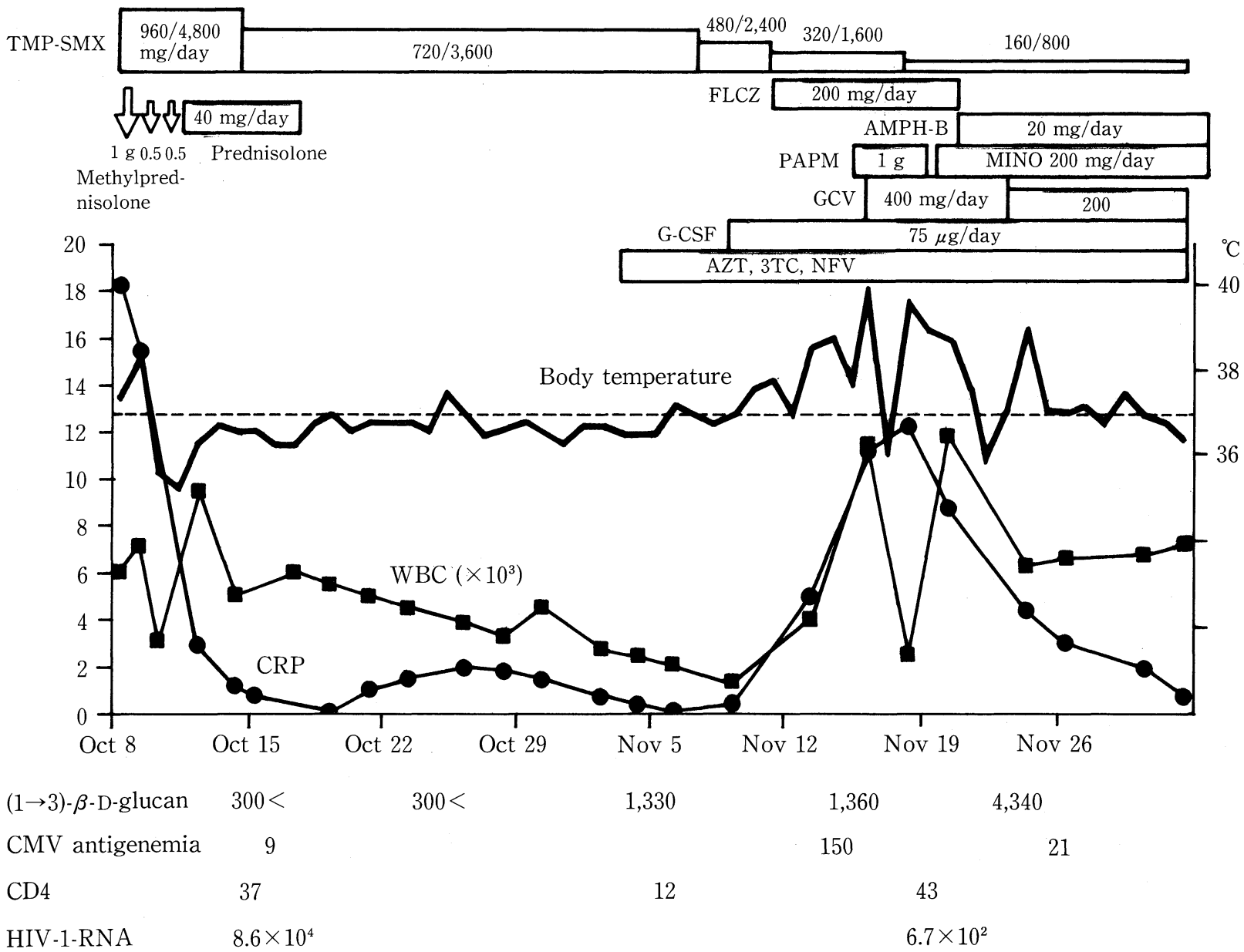

Figure 1. Clinical course of case 1. TMP-SMX: trimethoprim and sulfamethoxazole, FLCZ: fluconazole, AMPH-B: amphotericin B, PAPM: panipenem/betamiprom, MINO: minocycline hydrochloride, GCV: ganciclovir, G-CSF: granulocyte colony-stimulating factor, AZT: zidovudine, 3TC: lamivudine, NFV: nelfinavir, WBC: white blood cell, CRP: C reactive protein, CMV: Cytomegalovirus. 


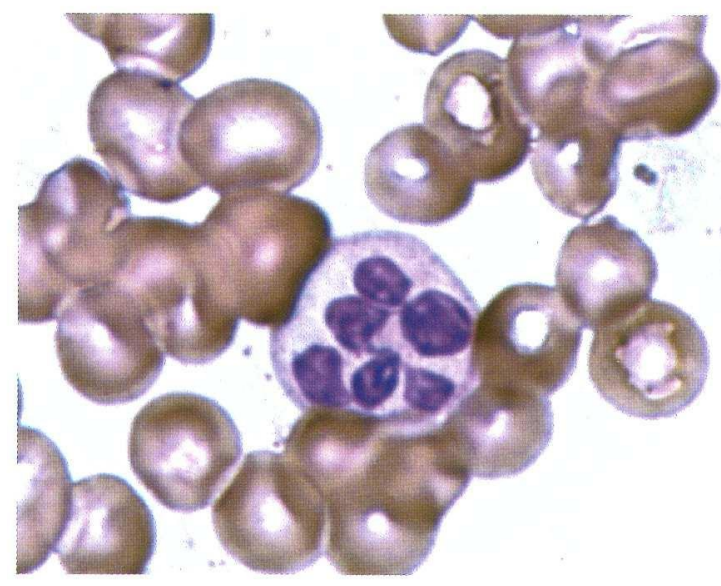

A

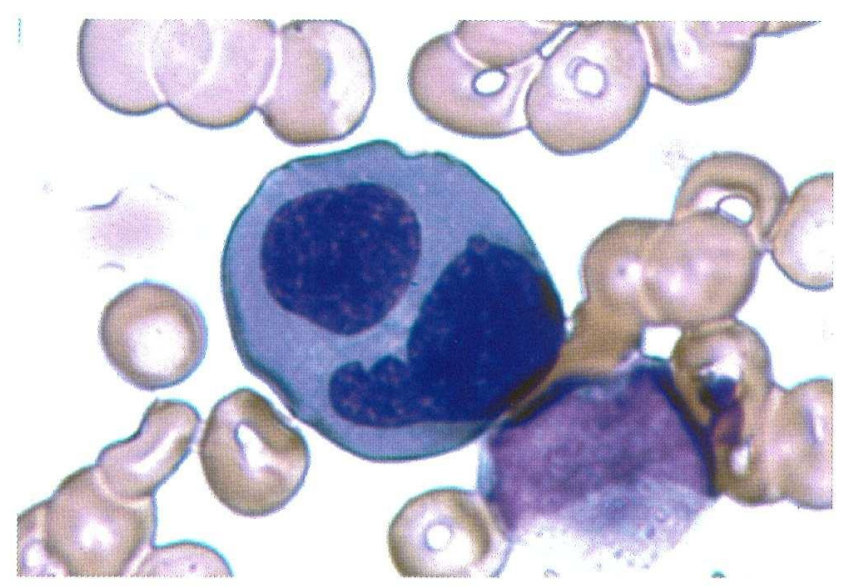

C

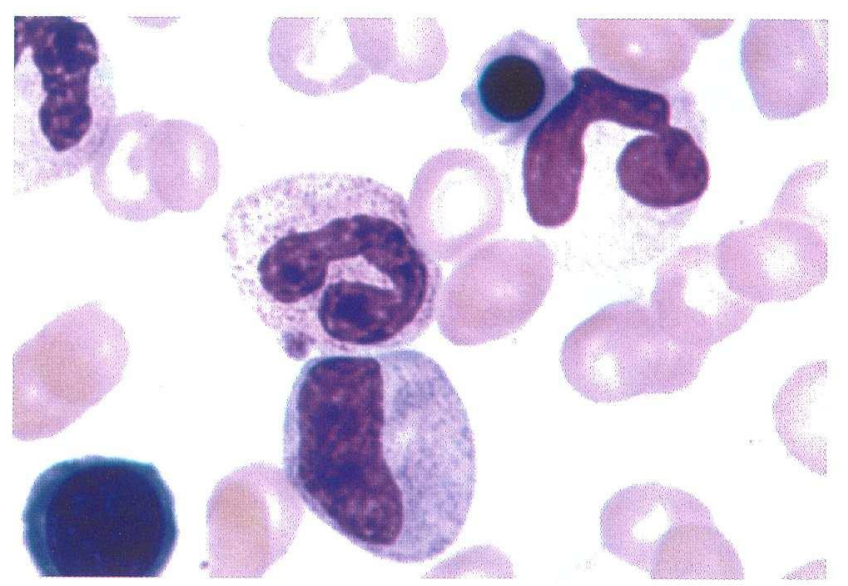

B

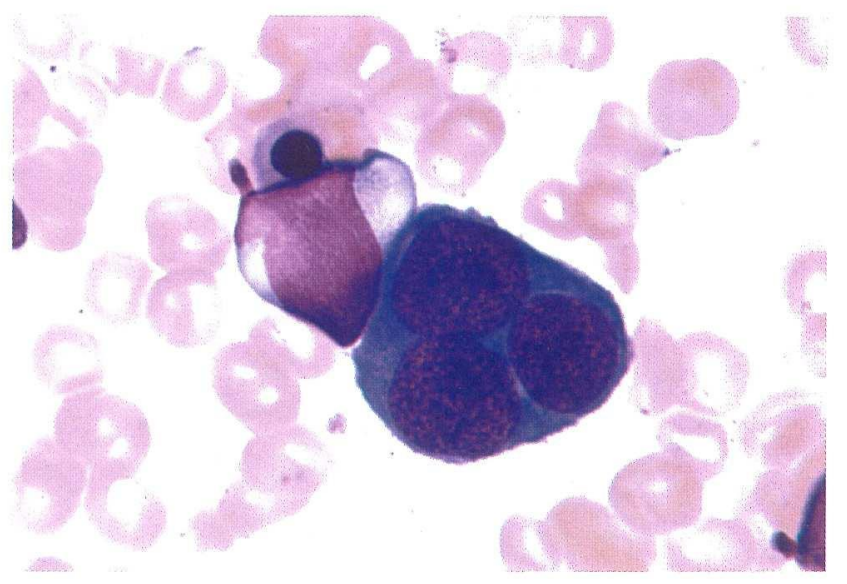

D

Figure 2. Morphologic abnormalities in bone marrow of case 1 (May-Giemsa stain, $\times 1$, 000). A: Hypersegmentation of neutrophils, B: Hypogranulation of neutrophils, C, D: Multinucleation of erythroblasts.

9.0-25.0). CD4+ cell count was $112 / \mu 1$ and viral load was less than 400 copies $/ \mathrm{ml}$. The serum level of vitamin B12 was high and folic acid was in the normal range. JC virus was detected from the CSF by PCR. He was diagnosed as having progressive multifocal leukoencephalopathy. BM aspirates were obtained for the examination of thrombocytopenia. BM specimen demonstrated slightly hypercellular marrow and morphologic abnormalities of hypo- or hypersegmentation, reduced or absent granulation of neutrophils, distorted nuclear and cytoplasmic maturation, and multinucleation of erythroblasts (Fig. 3). Neutrophil alkaline phosphatase (NAP) score was diminished to 139 (control 405). Chromosome analysis was 46, XY. These findings were similar to MDS. Although CD4+ cell count was increased to $268 / \mu \mathrm{l}$, his neural findings rapidly worsened and dysphagia appeared. After antiretroviral therapy was stopped, peripheral pancytopenia gradually progressed. WBC count was 1,300/ $\mu \mathrm{l}$ (neutrophils 61 , lymphocytes $29 \%$ ), hemoglobin $5.1 \mathrm{~g} / \mathrm{dl}$ and platelet count $2.3 \times 10^{4} / \mu \mathrm{l}$ in July 1998 . BM aspirates were obtained, and the findings were similar to the last one. He suffered from sepsis repeatedly (Staphylococcus epidermidis, Candida albicans, Pseudomonas aeruginosa, Citrobacter frenndii, Enterococcus faecalis, methicillin resistant Staphylococcus aureus) (Fig. 4).

\section{Discussion}

Pancytopenia is found in most patients with AIDS, particularly in the advanced phases. The mechanisms are commonly associated with the hematopoietic suppressive effects of HIV on HPC or marrow stromal cells, of certain types of infection (CMV, parvovirus, hepatitis virus and mycobacterial infection), or of drugs used in acquired immunodeficiency syndrome (AIDS)- related therapy (zidovudine, gancyclovir, TMP-SMX).

The most consistent HIV-related hematopoietic abnormality is the regenerative BM failure in which on-demand hematopoiesis is suppressed. There is clear evidence that HIV infec- 


\section{RYU et al}

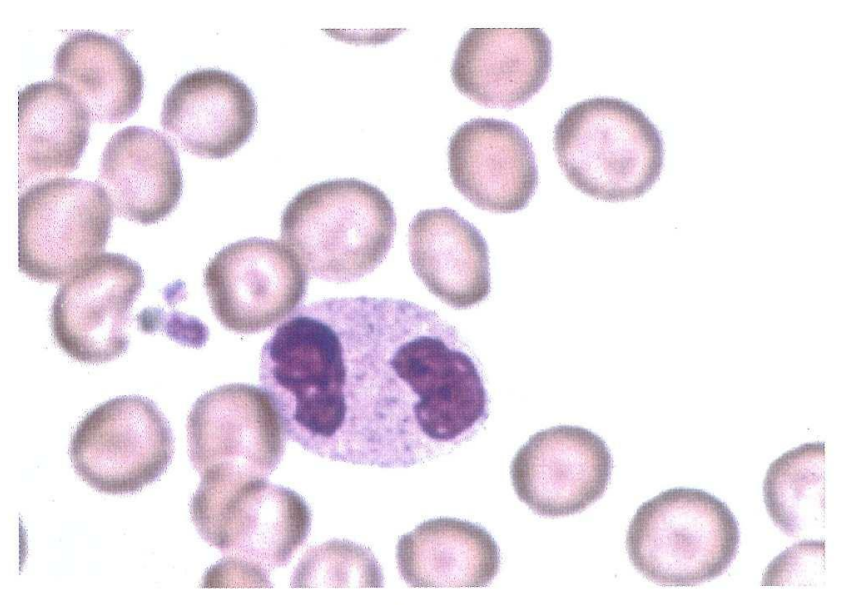

A

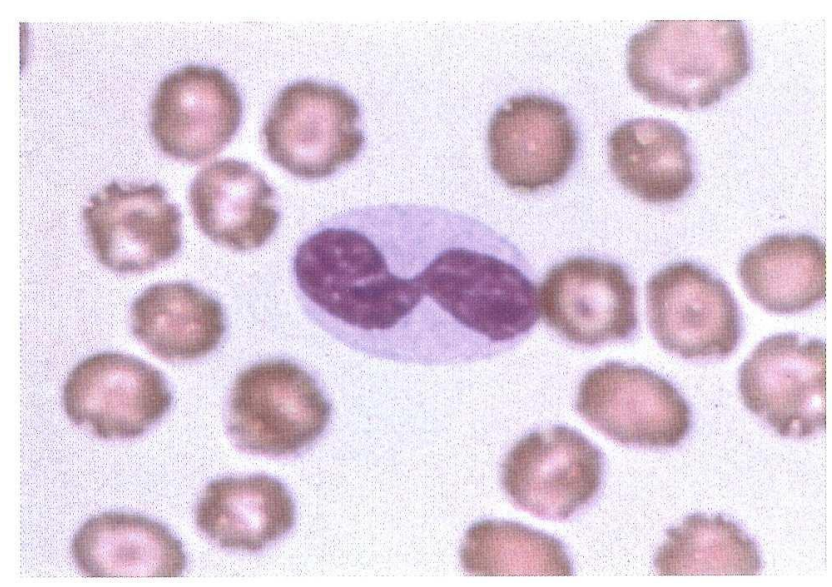

$\mathrm{C}$

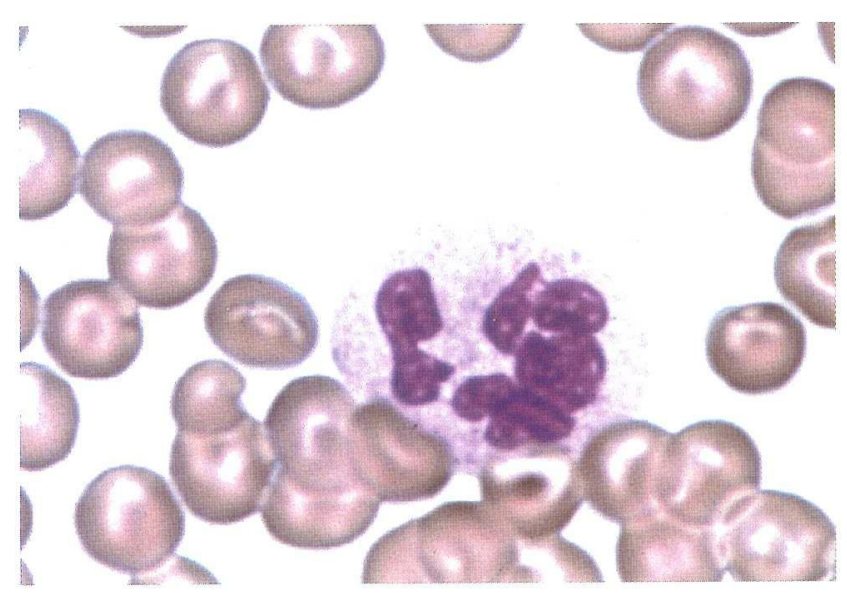

B

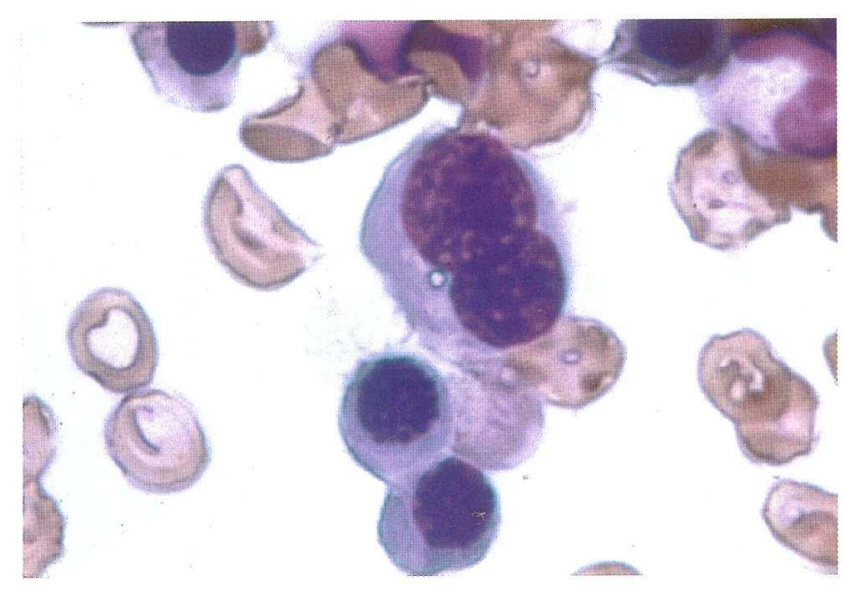

D

Figure 3. Morphologic abnormalities in bone marrow of case 2 (May-Giemsa stain, $\times 1,000$ ). A: Hyposegmentation of neutrophils, B: Hypersegmentation of neutrophils, C: Hypogranulation of neutrophils, D: Multinucleation of erythroblasts.

tion of auxiliary cells, mainly macrophages and microvascular endothelial cells (MVEC) (5) and viral gene products can indirectly influence survival and growth of HPC. The production of hematopoietic growth factors by HIV infected-auxiliary cells is normal, but lipopolysaccharide (LPS)-induced production of granulocyte-macrophage colony-stimulating factor (CSF), macrophage-CSF, G-CSF, interleukin (IL)-1 or IL-6 is significantly reduced (6). Moreover HIV inhibits replication of HPC by inducing release of multiple mitotic inhibitory factors $(7,8)$ and expression of factors known to induce apoptosis (9). These mechanisms can cause peripheral pancytopenia in association with BM failure. However, these studies have not suggested that HIV causes myelodysplasia or MDS.

On the other hand, myelodysplasia is also a common finding accompanying HIV infection. As dysplastic hematopoiesis in AIDS patients usually seems to be nonspecific change, it is called HIV-myelopathy. Cases of AIDS complicated with MDS seem to be rare $(10,11)$. As most patients with AIDS have already received myelotoxic therapy prior to marrow examination, it is difficult to specify the cause of dysplastic hematopoiesis. In other words, it is possible that the dysplastic changes could be related to drugs or infections. Inoue et al showed that long-term exposure of zidovudine produces myelodysplasia in mice (12). It is generally assumed that DNA elongation is stopped by the insertion of zidovudine into the chain in place of thymidine and therefore possible to link to the qualitative abnormality of HPC. Gancyclovir and TMP-SMX have not been reported to cause myelodysplasia. Viral infections usually can cause cytopenias in association with BM suppression. There are a few reports which discuss myelodysplasia caused by viral infection. Baurmann et al reported that bone marrow infection by parvovirus B 19 could closely mimic myelodysplasia (13).

We reported two cases of myelodysplasia associated with AIDS. In case 1, mild anemia, thrombocytopenia and hypersegmented neutrophils were observed before the admin- 
fever

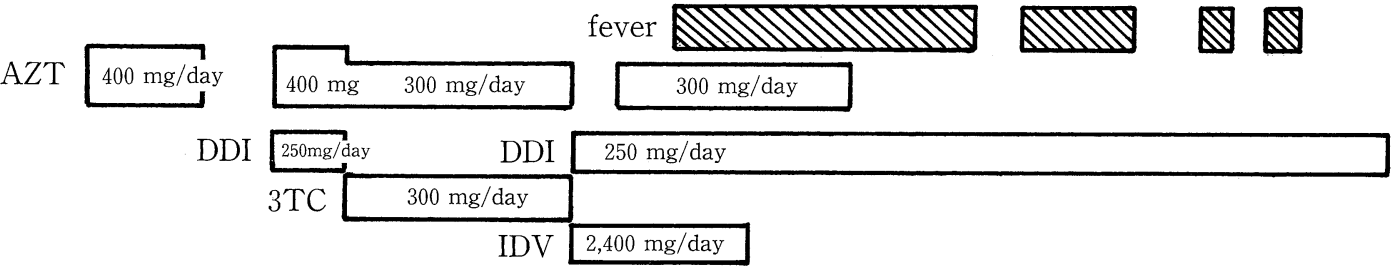

TMP-SMX

HIV-1-RNA

(copies/ml)

$$
\begin{array}{lllll}
5.0 \times 10^{4} & 5.5 \times 10^{4} & 1.3 \times 10^{3} & 3.4 \times 10^{3} & 8.8 \times 10^{4}
\end{array}
$$

$>7.5 \times 10^{5} \quad 5.4 \times 10^{4} \quad 4.4 \times 10^{4}$

$1.6 \times 10^{5}<400$

CD4 $(/ \mu 1)$
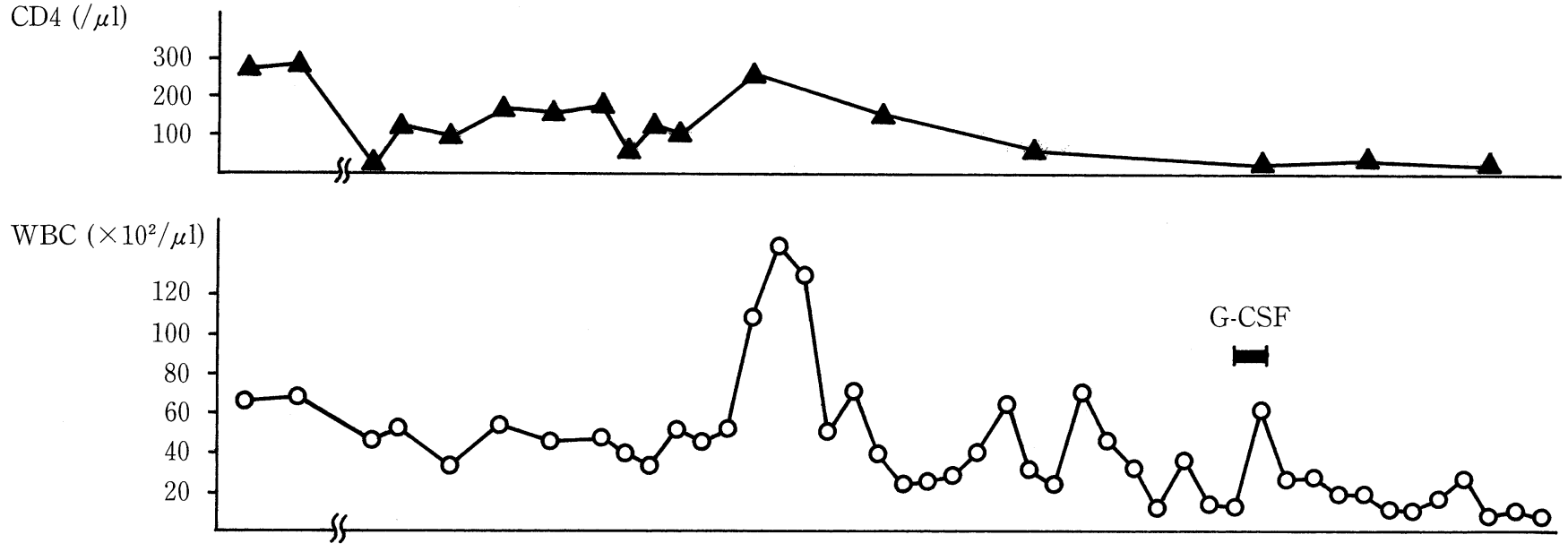

- $\mathrm{Hb}(\mathrm{g} / \mathrm{dl})$

- Plt $\left(\times 10^{4} / \mu 1\right)$

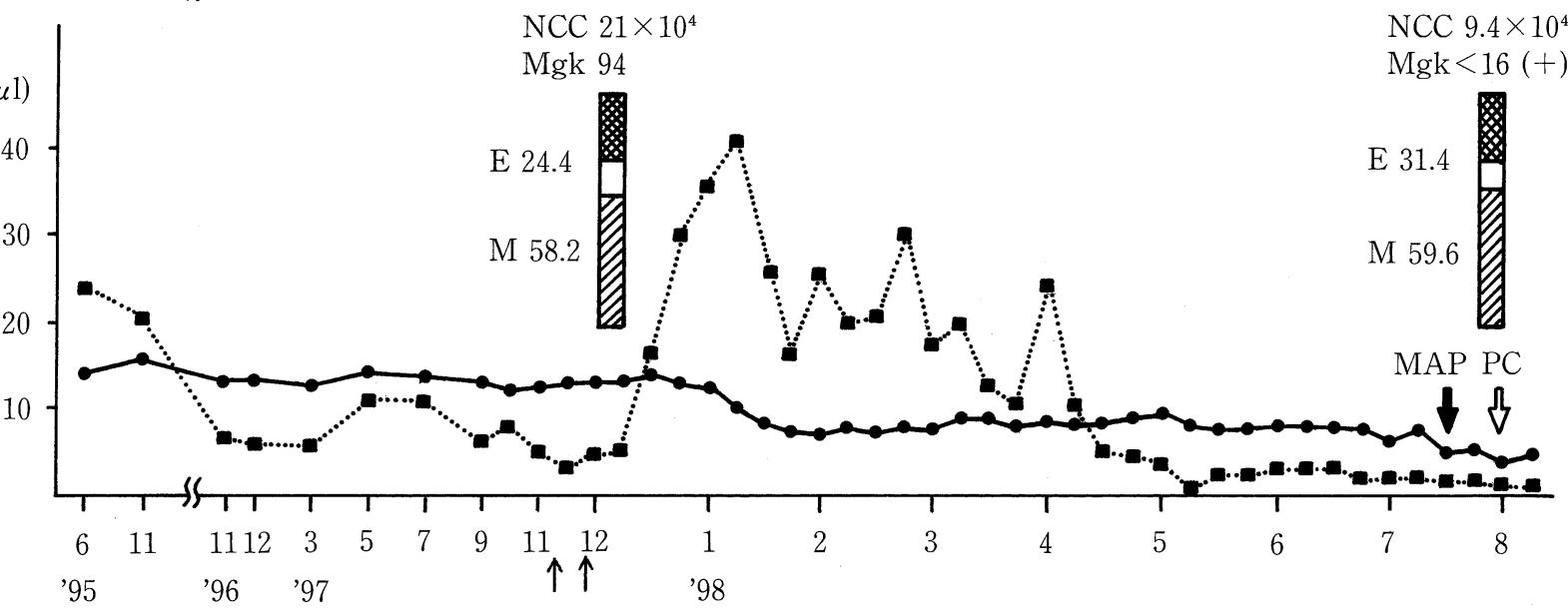

1st 2nd admission

Figure 4. Clinical course of case 2. AZT: zidovudine, DDI: didanosine, 3TC: lamivudine, IDV: indinavir sulfate ethanolate, TMP-SMX: trimethoprim and sulfamethoxazole, G-CSF: granulocyte colony-stimulating factor, WBC: white blood cell, Hb: hemoglobin, Plt: platelet, NCC: nucleated cells count, Mgk: megakaryocytes.

istration of TMP-SMX and antiretroviral therapy. The bone marrow findings of hypersegmented neutrophils and dysplastic erythroblasts suggested the abnormality of nucleic acid metabolism due to drugs, in addition to the inflammatory-reactive changes (HIV-myelopathy). The defects of nuclear lobulation of mature neutrophils and micromegakaryocytes which were features of MDS were not observed. In case 2, the BM specimen demonstrated slightly hypercellular marrow and morphologic abnormalities of pseudo-Pelger-Huët anomaly, hypersegmentation, reduced or absent granulation of neutrophils, distorted nuclear and cytoplasmic maturation, multinucleation of erythroblasts. NAP score was diminished. Peripheral pancytopenia has gradually progressed after discontinuation of antiretroviral therapy. These findings were similar to MDS (Table 1). Table 1 shows the comparison of hematologic changes between HIV-myelopathy and MDS (except for 


\section{RYU et al}

Table 1. Comparison of Hematologic Findings and Bone Marrow in Patients with HIV Infection and MDS $(3,4)$

\begin{tabular}{|c|c|c|c|c|}
\hline & HIV $(n=40)$ & $\operatorname{MDS}(n=40)$ & Case 1 & Case 2 \\
\hline Mean $\mathrm{Hb}(\mathrm{g} / \mathrm{dl})$ & 10.8 & $8.9^{*}$ & 10.4 & 5.1 \\
\hline Quality of anemia & normocytic & macrocytic & macrocytic & macrocytic \\
\hline Mean WBC $\left(\times 10^{3} / \mu 1\right)$ & 5.2 & $3^{*}$ & $2.7^{\circ}$ & 1.3 \\
\hline Mean plts $\left(\times 10^{3} / \mu \mathrm{l}\right)$ & 196 & 132 & 73 & 23 \\
\hline Bone marrow cellularity & $\rightarrow \sim \uparrow$ & $\uparrow \sim \uparrow \uparrow *$ & $\rightarrow$ & $\uparrow$ \\
\hline \multicolumn{5}{|l|}{ Granulopoiesis } \\
\hline increase of blasts & rare & + & - & - \\
\hline shift to the left & $+(50.0 \%)$ & + & + & - \\
\hline giant bands & $+(17.5 \%)$ & + & + & + \\
\hline increase of monocyte-like cells & $+(35.0 \%)$ & uncommon & - & - \\
\hline hypogranulation & uncommon & + & + & + \\
\hline hypersegmentation & uncommon & + & + & + \\
\hline hyposegmentation & uncommon & + & - & + \\
\hline \multicolumn{5}{|l|}{ Erythropoiesis } \\
\hline shift to the left & + & + & + & + \\
\hline macrocytic to megaloblastoid & not often & often* & + & + \\
\hline $\begin{array}{l}\text { defect in nuclear-cytoplasmic } \\
\text { maturation }\end{array}$ & not often & often* & + & + \\
\hline multinucleation & not often & often* & + & + \\
\hline \multicolumn{5}{|l|}{ Megakaryopoiesis } \\
\hline micromegakaryocytes & rare & $+*$ & - & - \\
\hline atypical lobulation & uncommon & often* & - & - \\
\hline
\end{tabular}

*statistical significance $\mathrm{p} \leqq 0.05$. HIV: human immunodeficiency virus, MDS: myelodysplastic syndrome, Hb: hemoglobin, WBC: white blood cell, plts: platelets.

chronic myelomonocytic leukemia and refractory anemia with excess of blasts in transformation). In contrast to the inconspicuous changes of hemopoietic cells in AIDS, MDS showed a variety of morphologic abnormalities $(3,4)$.

Because MDS results from an abnormality of HPC, it is very important to focus on the direct influence of HIV on HPC (14). Current studies suggest that HIV infection of HPC is infrequent and not substantially involved in the pathogenesis of marrow failure. However, it has already been shown that a small fraction of enriched marrow progenitors express both CD34+ and either CD4+ or gp120+ (15). Recently, it was shown that CXCR4 transcripts were detected in CD34+ cells (16). We observed that pathogenic simian/human immunodeficiency virus (SHIV) induced dysplastic hematopoiesis which might result from the effect on HPC (Yoshino $\mathrm{N}$ et al, manuscript in preparation). Based on these facts, HPC may be infectable under certain conditions.

Although thrombocytopenia is not common as an isolated early manifestation of MDS, thrombocytopenia was present at the time of diagnosis of MDS in case 2. As his PAIgG level was high, he might be diagnosed as HIV-related thrombocytopenia without evaluation of bone marrow findings. There are recent reports that megakaryocytes express CXCR4 and CD4 (17). It becomes important to evaluate the role of direct infection of these cells by HIV. It is possible that some of the pa- tients diagnosed as HIV-related thrombocytopenia may be MDS.

We suggest that HIV infection induces MDS which results from the direct influence on HPC and MDS contributes to peripheral pancytopenia through ineffective hematopoiesis. When peripheral blood cytopenia is observed in patients with AIDS, MDS should be included in the differential diagnosis.

\section{References}

1) Costello C. Haematological abnormalities in human immunodeficiency virus (HIV) disease. J Clin Pathol 41: 711-715, 1988.

2) Mir N, Costello C, Luckit J, Lindley R. HIV-disease and bone marrow changes: A study of 60 cases. Eur J Haematol 42: 339-343, 1989.

3) Kaloutsi V, Kohlmeyer U, Maschek H, et al. Comparison of bone marrow and hematologic findings in patients with human immunodeficiency virus infection and those with myelodysplastic syndromes and infectious diseases. Am J Clin Pathol 101: 123-129, 1994.

4) Thiele J, Zirbes TK, Bertsch HP, Titius BR, Lorenzen J, Fischer R. AIDSrelated bone marrow lesions-myelodysplastic features or predominant inflammatory-reactive changes (HIV-myelopathy)? A comparative morphometric study by immunohistochemistry with special emphasis on apoptosis and PCNA-labeling. Anal Cell Pathol 11: 141-157, 1996.

5) Moses AV, Williams S, Heneveld ML, et al. Human immunodeficiency virus infection of bone marrow endothelium reduces induction of stromal hematopoietic growth factors. Blood 87: 919-925, 1996.

6) Esser R, Glienke W, von Briesen H, Rübsamen-Waigmann H, Andreesen $R$. Differential regulation of proinflammatory and hematopoietic cytokines 


\section{Myelodysplasia and AIDS}

in human macrophages after infection with human immunodeficiency virus. Blood 88: 3474-3481, 1996.

7) Ludewig B, Gelderblom HR, Becker Y, Schafer A, Pauli G. Transmission of HIV-1 from productively infected mature Langerhans cells to primary CD4+T lymphocytes results in altered $\mathrm{T}$ cell responses with enhanced production of IFN.gamma and IL-10. Virology 215: 51-60, 1996.

8) Gallicchio VS, Tse KF, Morrow J, Hughes NK. Suppression of hematopoietic support function is associated with overexpression of interleukin4 and transforming growth factor-b1 in LP-BM5 murine-leukemia-virusinfected stromal cell lines. Acta Haematol 95: 204-212, 1996.

9) Nagafuji K, Shibuya T, Harada M, et al. Functional expression of Fas antigen (CD95) on hematopoietic progenitor cells. Blood 86: 883-889, 1995.

10) Schneider DR, Picker LJ. Myelodysplasia in the acquired immune deficiency syndrome. Am J Clin Pathol 84: 144-152, 1985.

11) Napoli VM, Stein SF, Spira TJ, Raskin D. Myelodysplasia progressing to acute myeloblastic leukemia in an HTLV-III virus-positive homosexual man with AIDS-related complex. Am J Clin Pathol 86: 788-791, 1986.
12) Inoue T, Cronkite EP, Hirabayashi $Y$, Bullis JE Jr, Mitsui H, Umemura T. Lifetime treatment of mice with Azidothymidine (AZT) produces myelodysplasia. Leukemia 11 Suppl 3: 123-127, 1997.

13) Baurmann H, Schwarz TF, Oertel J, Serke S, Roggendorf M, Huhn D. Acute parvovirus B19 infection mimicking myelodysplastic syndrome of the bone marrow. Ann Hematol 64: 43-45, 1992.

14) Moses A, Nelson J, Bagby GC Jr. The influence of human immunodeficiency virus-1 on hematopoiesis. Blood 91: 1479-1495, 1998.

15) Arock M, Dedenon A, Le Goff L, et al. Specific ligation of the HIV-1 viral envelope protein gp120 on human CD34+ bone marrow-derived progenitors. Cell Mol Biol 40: 319-323, 1994.

16) Deichmann M, Kronenwett R, Haas R. Expression of the human immunodeficiency virus type- 1 coreceptors CXCR-4 (fusin, LESTR) and CKR5 in CD34+ hematopoietic progenitor cells. Blood 89: 3522-3528, 1997.

17) Riviere $C$, Subra F, Cohen-Solal $K$, et al. Phenotypic and functional evidence for the expression of CXCR4 receptor during megakaryocytopoiesis. Blood 93: 1511-1523, 1999. 